\title{
The dog and cat population on Maio Island, Cape Verde: characterisation and prediction based on household survey and remotely sensed imagery
}

\author{
Ana Carolina Lopes Antunes, ${ }^{1}$ Els Ducheyne, ${ }^{2}$ Ward Bryssinckx, ${ }^{2}$ Sara Vieira, ${ }^{3}$ \\ Manuel Malta, ${ }^{4}$ Yolanda Vaz, ${ }^{5}$ Telmo Nunes, ${ }^{5}$ Koen Mintiens ${ }^{2}$ \\ ${ }^{1}$ National Veterinary Institute, Technical University of Denmark, Frederiksberg, Denmark; \\ ${ }^{2}$ Avia-GIS, Zoersel, Belgium; ${ }^{3}$ Ministry of Rural Development, Maio, Cape Verde; \\ ${ }^{4}$ Veterinarians Without Borders, Lisbon; ${ }^{5}$ Faculty of Veterinary Medicine, University of \\ Lisbon, Portugal
}

\begin{abstract}
The objective was to estimate and characterise the dog and cat population on Maio Island, Cape Verde. Remotely sensed imagery was used to document the number of houses across the island and a household survey was carried out in six administrative areas recording the location of each animal using a global positioning system instrument. Linear statistical models were applied to predict the dog and cat populations based on the number of houses found and according to various levels of data aggregation. In the surveyed localities, a total of 457 dogs and 306 cats were found. The majority of animals had owners and only a few had free access to outdoor activities. The estimated population size was 531 dogs [ $95 \%$ confidence interval (CI): 453-609] and 354 cats (95\% CI: 275-431). Stray animals were not a concern on the island in contrast to the rest of the country.
\end{abstract}

Correspondence: Ana Carolina Lopes Antunes, Section of Epidemiology, National Veterinary Institute, Technical University of Denmark, Bülowsvej 27, 1870 Frederiksberg C, Denmark.

Tel: +35.3588 .6858 - Fax: +35.3588 .6001 .

E-mail: aclan@vet.dtu.dk

Key words: Dog; Cat; Household survey; Remote sensing; Maio Island.

Acknowledgments: the authors would like to thank to VSF-Portugal and Maio municipally for supporting the accommodation on Maio Island and to the Agriculture, Forestry and Animal Husbandry Services of Cape Verde for providing transportation on the island to perform the survey.

Contributions: ACLA, data collection and manuscript writing; ACLA, ED, WB and TM, data analysis; ED manuscripts reviewing; ACLA, SV, MM, YV, TN and KM, study coordination.

Conflict of interest: the authors declare no potential conflict of interest.

Received for publication: 13 June 2015.

Revision received: 28 August 2015.

Accepted for publication: 29 August 2015.

(C) Copyright A.C. Lopes Antunes et al., 2015

Licensee PAGEPress, Italy

Geospatial Health 2015; 10:386

doi:10.4081/gh.2015.386

This article is distributed under the terms of the Creative Commons Attribution Noncommercial License (by-nc 3.0) which permits any noncommercial use, distribution, and reproduction in any medium, provided the original author(s) and source are credited.

\section{Introduction}

One Health (http://www.onehealthglobal.net/) tends to focus on zoonotic pathogens emerging from wildlife and production animal species (Day, 2011). However, this underestimates the impact of companion animals, which are responsible for transmitting several zoonotic diseases, such as toxoplasmosis, Lyme disease and rabies in many parts of the world. In fact, rabies remains one of the most serious zoonoses worldwide as indicated by World Health Organization (WHO) documentation (WHO, 2014a). Despite the fact that there are no current reports of a major zoonotic disease in Cape Verde (WHO, 2014b), its geographical location facilitates the introduction of such diseases from other countries due to the country's situation near the African continent and part of the world's global transport network. These facts highlight the importance of functioning surveillance programmes, including emergency plans with respect to certain diseases. There are no official records on the dog and cat population in Cape Verde. Still, stray dogs are a major concern in this country as they could have an impact on public health and environment due to risk of the potential of introduction of transmissible zoonoses. In addition, physical injury resulting from dog bites would have a negative effect on tourism. Our study was done in order to plan animal health and welfare campaigns and define future surveillance programmes. The specific objective was to estimate and characterize the dog and cat populations on Maio Island, the easternmost of the Sotavento islands of Cape Verde. It was done in parallel with a mission carried out by the Veterinarians Without Borders (Vétérinaires sans Frontières, VSF) from Portugal.

\section{Materials and Methods}

\section{Data collection}

Despite the fact that many of the animals under study in Cape Verde roam freely on the streets, almost all of them have an owner. A household survey was designed to collect information on the dog and cat populations during the mission of VSF-Portugal on Maio Island that took place from $15^{\text {th }}$ to $24^{\text {th }}$ October, 2012. The survey was conducted in six of the 14 administrative areas of the island, i.e. Alcatraz, Calheta, Figueira da Horta, Morrinho, Morro and Porto Inglês. These different localities were selected and the houses visited according to a predefined plan based on the island's Livestock Services (http://www.mdr.gov.cv/).

The survey included all households from the six localities chosen 
and the response rate was $100 \%$. When an animal was spotted in the street, local residents were asked about its owner to find out whether or not they were stray animals. The survey was based on a questionnaire used during the VSF-Portugal campaign and the coordinates of the animals' place of feeding (the household locations) were recorded for each dog and cat using a global positioning system (GPS) instrument (Garmin ${ }^{\circledR}$ Etrex 20; Garmin, Schaffhausen, Switzerland). The questionnaires included questions intended to provide clinical information on the each animal's health.

The total number of people in each locality of the island was provided by Census 2010 (INE, 2012). In order to calculate the number of houses, their location and the urban areas across the island, remotely sensed imagery was obtained from Google ${ }^{\mathrm{TM}}$ Earth. The most recent available images (March 2013) were selected. The number of houses was used as a proxy for the number of households in order to estimate the animal populations. A grid with $20 \mathrm{~km}$ side length and $100 \times 100 \mathrm{~m}$ cell units, i.e. 1 hectare, was used to calculate the house density as well as that of the dogs and cats across the island. Porto Inglês, the major city in the southwestern part of Maio island, was divided into a set of sub-regions (blocks) with $200 \mathrm{~m}^{2}$ size due to its larger dimension. This was based on a geographical information systems (GIS) approach using Quantum GIS 1.8 software (http://www.qgis.org/) and Google ${ }^{\mathrm{TM}}$ Earth imagery.

\section{Data processing and analysis}

The data were aggregated using different metric resolutions (200, $400,500,800$ and 1000). These resolutions were chosen to avoid any disparity in overlapping of different variables when performing the spatial analysis. In order to measure the strength of any relationship between the densities of dogs, cats and houses, the Spearman's Rank Correlation Coefficients were calculated for the different resolutions mentioned. Based on these results and on the spatial accuracy to locate the animals, it was decided to build linear regression models of 200 and $400 \mathrm{~m}$ for both species, with the number of houses defined as the predictor variable. The residuals were mapped for the models based on 200 $\mathrm{m}$ in order to evaluate their distribution. K-fold cross-validation $(\mathrm{K}=3)$ was performed in order to assess the fitness of the models.
The household and animal densities and the spatial aggregation were calculated and performed using ArcGIS ${ }^{\circledR} 10.1$ software (ESRI, Redlands, CA, USA). The analysis was carried out using R, version 3.0.2 (R Development Core Team, 2013). Cross validation was carried out in using the $\mathrm{R}$ library data analysis and graphics (DAAG) function (Maindonald and Braun, 2013).

\section{Results}

\section{Demographic data and survey results}

All dogs and cats had a normal body condition. Only one male dog was reported with skin problems, which included alopecia, crust and peeling. Table 1 shows the number of households, resident population and urban areas for each locality on Maio Island. Based on Google ${ }^{\mathrm{TM}}$ Earth imagery, a total of 2485 households were identified and digitized. The total number of 457 dogs and 306 cats were identified in the six surveyed localities.

Porto Inglês had the highest number of animals (272 dogs and 156 cats) and it was also the area with the highest percentage of sterilized and dewormed animals: $19.69 \%$ of the dogs and $26.04 \%$ of the cats were sterilized, while $26.04 \%$ of the dogs and $16.01 \%$ of the cats were dewormed. The majority of the dogs and cats were classified as restricted (59.3\% of dogs and $60.5 \%$ of cats) and as semi-restricted but fully dependent (38.7\% of dogs and $36.9 \%$ of cats). Porto Inglês was the only locality where stray animals (both species) were reported.

Dogs and/or cats were found in 514 out of the total number of households $(\mathrm{n}=1978)$, which demonstrate that $26 \%$ of the total number of households had at least one animal (Table 2). The average number of animals per household was higher for dogs in Morro (1.6) and for cats in Calheta (1.58). The lowest number of dogs per household was found in Alcatraz (1) and for cats in Alcatraz and Morro (1). The dog density (per $\mathrm{m}^{2}$ ) was higher than the cat density for all localities except in Figueira da Horta.

Table 1. Results of the locality survey on Maio Island, Cape Verde.

\begin{tabular}{|c|c|c|c|c|c|}
\hline Locality & Resident population $^{\circ}$ (n) & Households\# (n) & Urban area $\left(\mathrm{m}^{2}\right)$ & Dogs (n) & Cats (n) \\
\hline Alcatraz ${ }^{\S}$ & 232 & 70 & 22,189 & 12 & 5 \\
\hline Calheta ${ }^{\S}$ & 1156 & 290 & 184,140 & 72 & 63 \\
\hline Porto Inglês ${ }^{\S}$ & 2971 & 1195 & $1,624,238$ & 272 & 156 \\
\hline Figueira da Horta ${ }^{\S}$ & 446 & 171 & 56,907 & 27 & 42 \\
\hline Morrinho $0^{\S}$ & 444 & 131 & 60,461 & 34 & 26 \\
\hline Morro $\$$ & 310 & 121 & 71,325 & 40 & 14 \\
\hline Barreiro & 535 & 176 & - & - & - \\
\hline Cascabulho & 204 & 75 & - & - & - \\
\hline Figueira Seca & 83 & 31 & - & - & - \\
\hline Pedro Vaz & 166 & 69 & - & - & - \\
\hline Pilão Cão & 102 & 46 & - & - & - \\
\hline Praia Goncalo & 67 & 29 & - & - & - \\
\hline Ribeira D. João & 203 & 70 & - & - & - \\
\hline Santo António & 22 & 10 & - & - & - \\
\hline Monte Farenegro & - & 1 & - & - & - \\
\hline Total & 6941 & 2485 & - & - & - \\
\hline
\end{tabular}

${ }^{\circ}$ Census 2010 (INE, 2012); ${ }^{\#}$ estimate based on Google ${ }^{\text {TM }}$ Earth imagery; ${ }^{\S}$ visited localities. 


\section{Spatial analysis}

Figure 1 represents dog and cat density distributions in Porto Inglês. The correlation between dog-house and cat-house densities increased with the spatial aggregation from $0.58(\mathrm{P}<0.001)$ to $0.88(\mathrm{P}<0.001)$ and $0.43(\mathrm{P}<0.001)$ to $0.94(\mathrm{P}<0.001)$, respectively. The linear regression models we used to estimate dog and cat population are represented in Figure 2. The residuals of the models were normally distributed. Figures 3 and 4 show the residuals distribution in Porto Inglês for the models based on the $200 \mathrm{~m}$ resolution.

Cross validation results revealed that the mean square prediction error (MSPE) was higher for the model based on the $400 \mathrm{~m}$ resolution (59.8) when compared with the $200 \mathrm{~m}$ resolution (39.1) for the dog population; similar results were found for the cat population, in which the MSPE was higher for the $400 \mathrm{~m}$ resolution (104) when compared to $200 \mathrm{~m}$ resolution model (19.9). Comparing the predicted results for the dog and cat population with the results gathered during the survey in the visited locations, the linear models underestimated both animal population (Table 3). The model based on the $400 \mathrm{~m}$ resolution performed better (error of 7.4\%) when compared to the model based on the $200 \mathrm{~m}$ resolution (error of 11.8\%) for the dog population estimate; the model based on the $200 \mathrm{~m}$ resolution presented a lower error (7.84\%) when compared to the $400 \mathrm{~m}$ resolution model (19.61\%) in cats. Therefore, it was decided that the model based on the $400 \mathrm{~m}$ and $200 \mathrm{~m}$ resolutions was the best for the prediction of the dog and cat populations, respectively. The predicted population size was 531 dogs [ $95 \%$ confidence interval (CI): 453-609] (Figure 5) and 354 cats (95\% CI: 275-431) (Figure 6).

\section{Discussion}

Several sterilisation and deworming campaigns have been performed over the last years on the island, though they were centralized

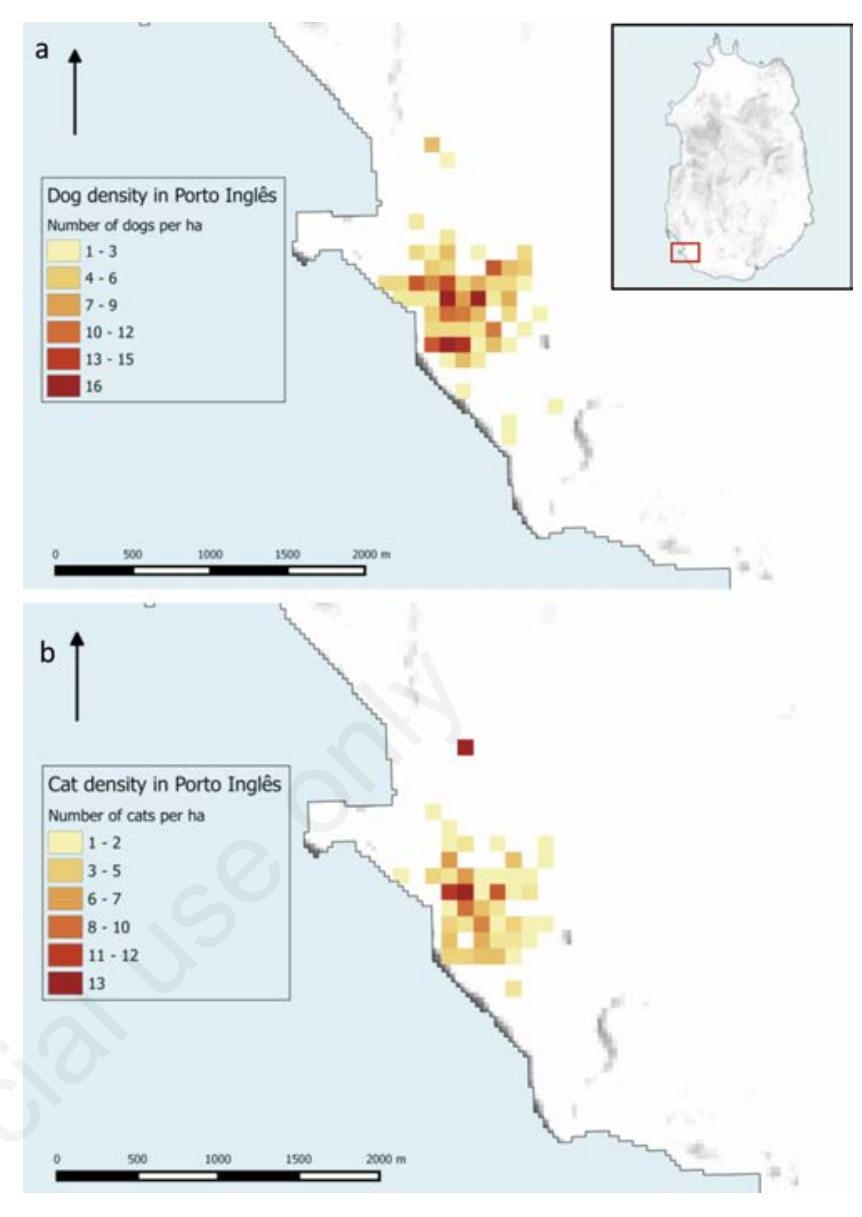

Figure 1. The density distribution of dogs (a) and cats (b) in Porto Inglês, Cape Verde.

Table 2. Households and animals in the surveyed localities on Maio Island, Cape Verde.

\begin{tabular}{|c|c|c|c|c|c|c|c|c|}
\hline Locality & $\begin{array}{l}\text { Households } \\
\text { (n) }\end{array}$ & $\begin{array}{l}\text { Households with } \\
\text { dogs (n) }\end{array}$ & $\begin{array}{l}\text { Households with } \\
\text { cats (n) }\end{array}$ & $\begin{array}{c}\text { Households with } \\
\text { both dogs and cats (n) }\end{array}$ & Dog/m² & $\begin{array}{l}\text { Dogs per person } \\
\text { (ratio) }\end{array}$ & $\mathrm{Cat} / \mathrm{m}^{2}$ & $\begin{array}{c}\text { Cats per } \\
\text { person (ratio) }\end{array}$ \\
\hline Alcatraz & 70 & 12 & 5 & 2 & 0.0005 & $1: 19$ & 0.0002 & 1:46 \\
\hline Calheta & 290 & 49 & 40 & 18 & 0.0004 & 1:16 & 0.0003 & 1:18 \\
\hline Figueira da Horta & 171 & 21 & 34 & 4 & 0.0005 & 1:17 & 0.0007 & 1:11 \\
\hline Morrinho & 131 & 24 & 17 & 10 & 0.0006 & $1: 13$ & 0.0004 & $1: 17$ \\
\hline Morro & 121 & 24 & 14 & 10 & 0.0006 & 1:08 & 0.0002 & 1:22 \\
\hline Porto Inglês & 1195 & 263 & 151 & 105 & 0.0002 & 1:11 & 0.0001 & 1:19 \\
\hline Total & 1978 & 418 & 270 & 149 & 0.0003 & 1:12 & 0.0002 & 1:18 \\
\hline
\end{tabular}

Table 3. Model results and error rates for the six visited localities on Maio Island, Cape Verde.

\begin{tabular}{lcccccc}
\hline Animal & Resolution (m) used & Number observed & Number predicted & Error (n) & & Error (\%) \\
Dog & 200 & 457 & 403 & 54 & 34 & 11.8 \\
\hline \multirow{2}{*}{ Cat } & 400 & 457 & 423 & 24 & 7.4 \\
& 200 & 306 & 282 & 60 & 1.84 \\
\hline
\end{tabular}


in Porto Inglês. This explained the fact that sterilised animals were only identified in Porto Inglês and in Morro, the nearest village. Regarding the type of restriction and dependence, it was possible to verify that a high percentage of animals lived indoors with limited street access, thus highlighting the importance, affection and esteem of these animals in this community. This is somewhat surprising since the presence of stray dogs was reported in all islands of Cape Verde.

Very few stray animals were encountered thanks to the work done by VSF-Portugal on this island in recent years, which has contributed strongly to control the free-roaming animal populations. The few stray animals reported could in fact belong to someone living in a different area of Porto Inglês. The animal to human ratio obtained for visited localities on Maio Island were similar to the ratios obtained in Zimbabwe (Brooks, 1990), Tanzania (Knobel et al., 2008) and Chad
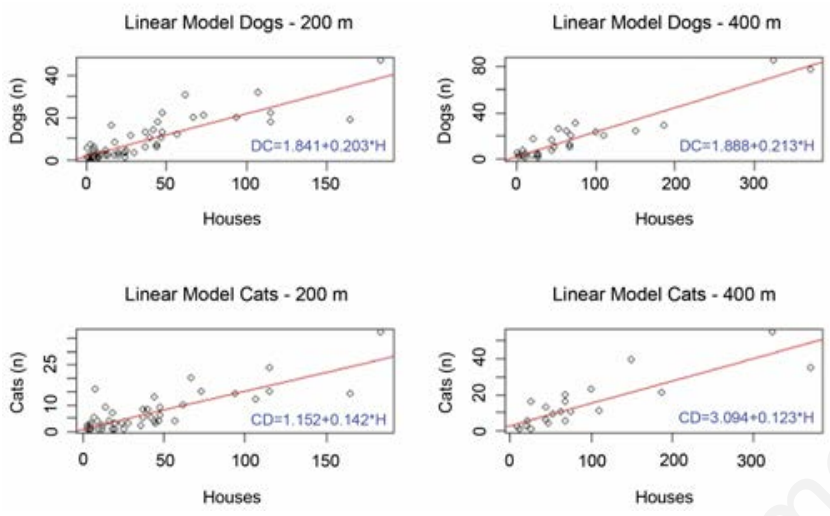

Figure 2. Linear regression models for estimating the population of dogs and cats based on 200 and $400 \mathrm{~m}$ resolution of data aggregation on Maio Island, Cape Verde.

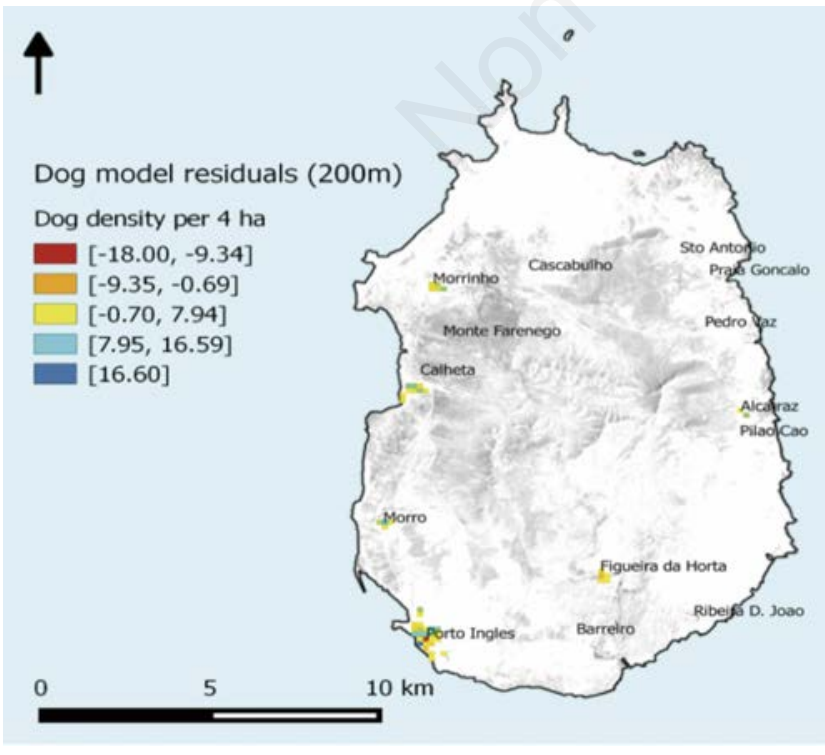

Figure 3. Dog model residuals distribution based on the $200 \mathrm{~m}$ resolution of data aggregation.
(Mindekem et al., 2005) for urban areas.

Significant differences on the proportions of gender and sterilised animals where found when the VSF database and the survey results were compared. This should be expected since animal owners are more concerned about sterilisation of the female animals and their health

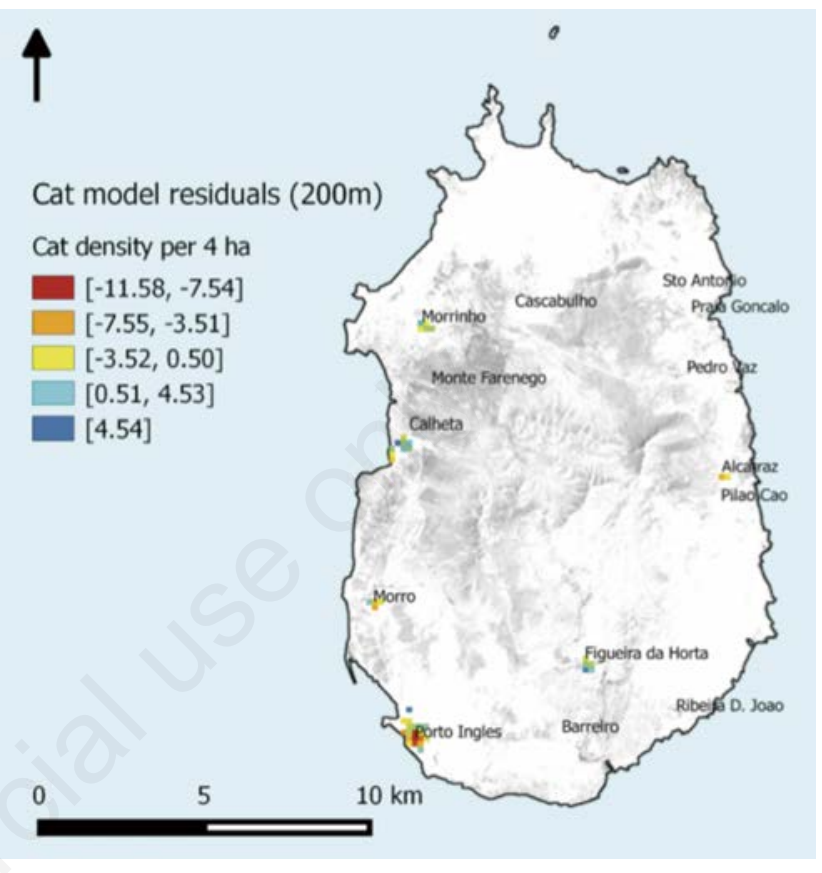

Figure 4. Cat model residuals distribution based on the $200 \mathrm{~m}$ resolution of data aggregation.

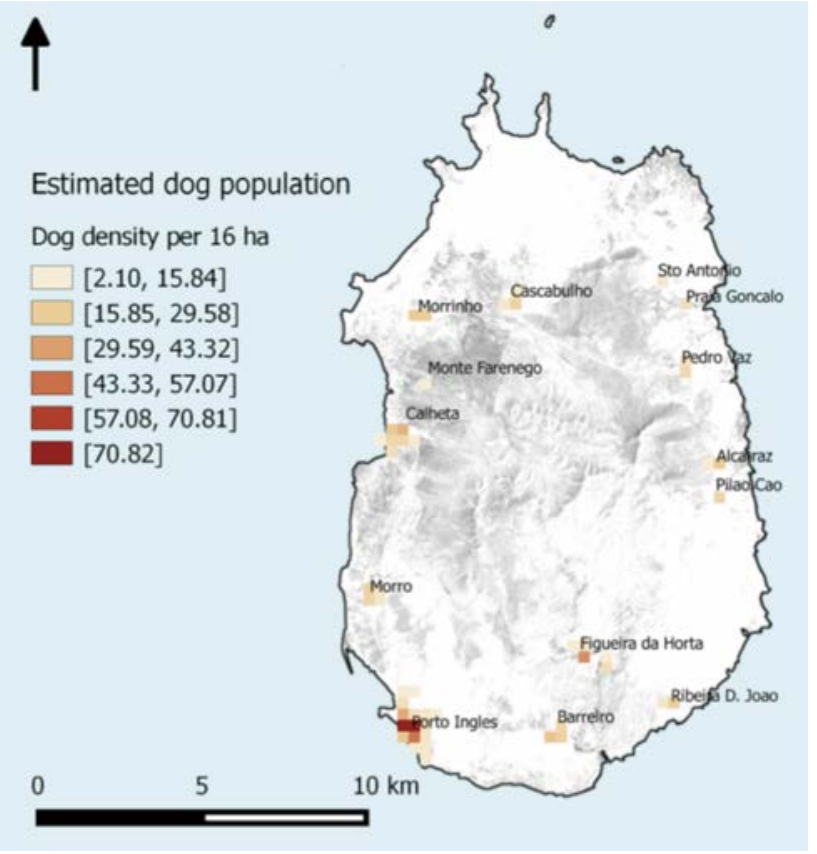

Figure 5. Dog population estimate and distribution on Maio Island, Cape Verde. 


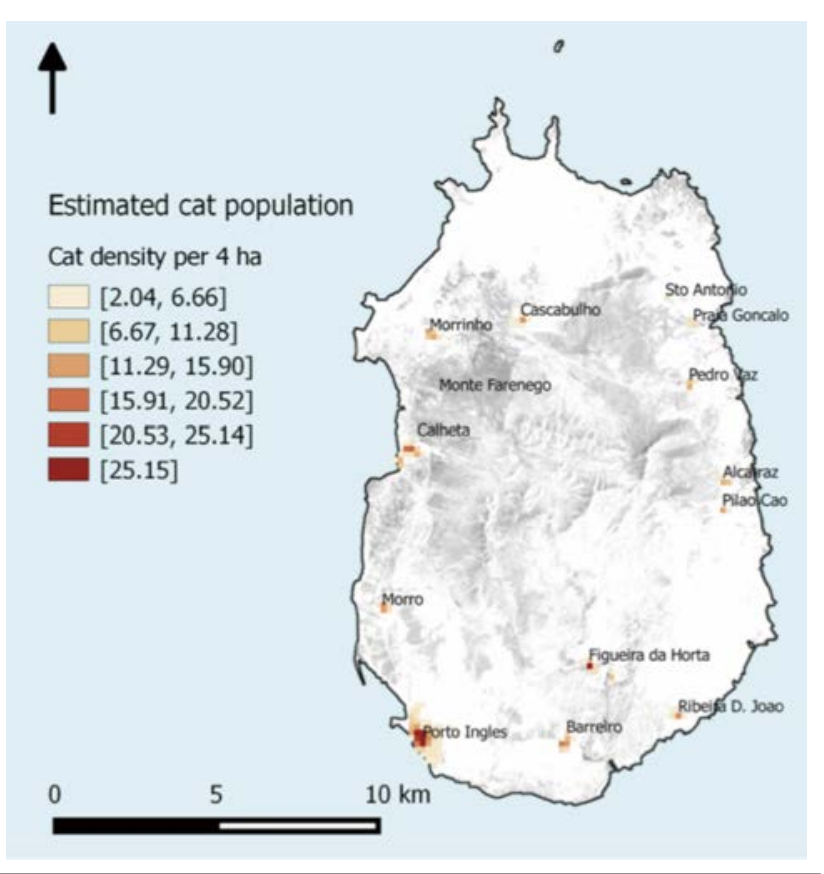

Figure 6. Cat population estimate and distribution on Maio Island, Cape Verde.

has a very important impact in controlling animal populations, resulting in a higher number of females being clinically examined during the VSF-Portugal campaign. For this study, remotely sensed data from Google $^{\mathrm{TM}}$ Earth imagery were used to estimate the number of houses across the island. However, this approach has several limitations: it does not allow us to distinguish between households and commercial or governmental buildings; in addition, it is not possible to quantify the number of households per building and the resolution might not allow identification of all buildings; finally, remote sensing assumes that all houses identified are occupied. This approach would not be suitable for highly populated areas where satellite image are not available or are of low quality. To overcome these issues, other remotely sensed data, such as night-time imagery, enhanced vegetation index (EVI), digital elevation model (DEM) and spectral radiance could be used (Li and Weng, 2005; Yang et al., 2013). In our case, this limitation was not a strong one as highly populated areas are not common on Maio Island.

Using a GIS approach, Rinzin (2007) found a positive relationship between human, dog and cat population densities in a region of New Zealand, which shows the potential of applying GIS for the estimation and characterisation of the distribution of animal populations. To our knowledge, GIS software has not been used for this purpose in Africa. We found the GIS technique to be crucial to find the relationship between animal and human counts.

According to the model, the number of observed animals was underestimated for areas corresponding to residuals with negative values. This was the case with regard to Porto Inglês that is the main city on the island, with the highest human population and the highest house density including several commercial and governmental buildings. One possible explanation for this could be the fact that the images used to calculate the house density did not allow differentiation between commercial, governmental and household buildings resulting in an overestimation of the number of houses, especially for areas where the density was shown to be very high. In addition, house limits cannot be clearly distinguished potentially resulting in double-counts due to suf- ficient contrast in the remotely sensed images. For other areas where the residuals had positive values, the number of animals could have been overestimated, which might result from the fact that Google ${ }^{\mathrm{TM}}$ Earth images cannot provide information on the number of floors of the buildings shown. These examples illustrate the disadvantages previously mentioned with respect to using Google ${ }^{\mathrm{TM}}$ Earth images for the calculation of house density. The models used may be more useful in urban environments for which detailed imagery is more commonly available and where the number of stray animals is expected to be low.

\section{Conclusions}

This study aimed to estimate and characterise the dog and cat population on Maio Island, Cape Verde. The great majority of animals had an owner and only few of them had free access to the outdoors. The results reveal that stray animals were not a concern on the island in contrast to the rest of the country. The predictive method used to estimate the animal population should be of best use in urban environments due to the availability of more detailed imagery and where the number of stray animals can be expected to be low.

\section{References}

Brooks R, 1990. Survey of the dog population of Zimbabwe and its level of rabies vaccination. Vet Rec 127:592-6.

Day MJ, 2011. One health: the importance of companion animal vectorborne diseases. Parasite Vector 4:49.

INE, 2012. Census 2010. Available from: http://www.ine.cv /censo/censo2010.aspx

Knobel DL, Laurenson MK, Kazwala RR, Boden LA, Cleaveland S, 2008. A cross-sectional study of factors associated with dog ownership in Tanzania. BMC Vet Res 4:5.

Li G, Weng Q, 2005. Using Landsat ETM+Imagery to measure population density in Indianapolis, Indiana, USA. Photogramm Eng Rem S 71:947-58.

Maindonald J, Braun WJ, 2013. Data analysis and graphics data and functions. Available from: http://artax.karlin.mff.cuni.cz/rhelp/library/DAAG/html/00Index.html

Mindekem R, Kayali U, Yemadji N, Ndoutamia AG, Zinsstag J, 2005. Impact of canine demography on rabies transmission in N'djamena, Chad. Med Trop (Mars) 65:53-8.

Rinzin K, 2007. The epidemiology of free-roaming dog and cat populations in the Wellington Region of New Zealand. MA Thesis. Institute of Veterinary, Animal and Biomedical Sciences, Massey University, Palmerston North, New Zealand.

R Development Core Team, 2013. R: a language and environment for statistical computing. Available from: https://www.r-project.org/

WHO, 2014a. Rabies. Available from: http://www.who.int/ mediacentre/factsheets/fs099/en/

WHO, 2014b. World Animal Health Information Database (WAHID) interface. Available from: http://www.oie.int/wahis_2/ public/wahid.php/Diseaseinformation/Diseaseoutbreakmaps

Yang X, Yue W, Gao D, 2013. Spatial improvement of human population distribution based on multi-sensor remote-sensing data: an input for exposure assessment. Int J Remote Sens 34:5569-83. 